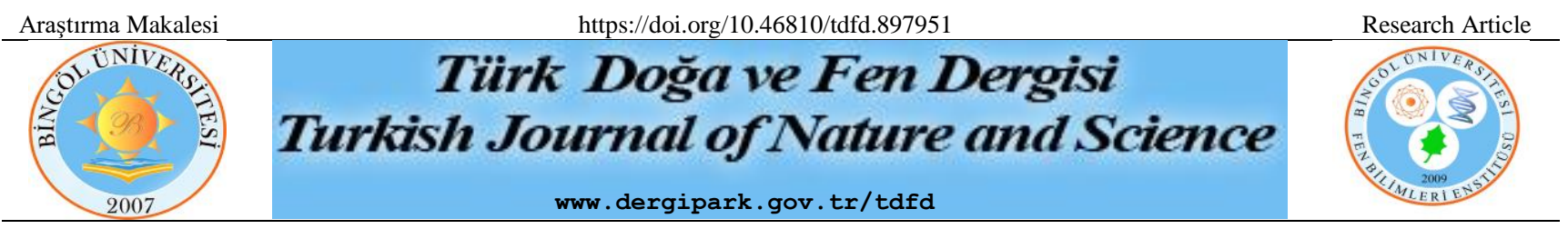

\title{
Sismik Taban Yalıtımlı Yapılarda Zaman Tanım Alanında Analiz ve Artımsal Tek Modlu İtme Yöntemlerinin Karşılaştırılması
}

\author{
Elif TOPLU ${ }^{1}$, Osman KIRTEL ${ }^{2 *}$ \\ ${ }^{1}$ Sakarya Uygulamalı Bilimler Üniversitesi, Teknoloji Fakültesi, İnşaat Mühendisliği Bölümü, Sakarya, Türkiye \\ ${ }^{2}$ Sakarya Uygulamalı Bilimler Üniversitesi, Teknoloji Fakültesi, İnşaat Mühendisliği Bölümü, Sakarya, Türkiye \\ Elif TOPLU ORCID No: 0000-0001-8019-560X \\ Osman KIRTEL ORCID No: 0000-0001-6451-0323
}

*Sorumlu yazar: okirtel@subu.edu.tr

(Alınış: 16.03.2021, Kabul: 24.05.2021, Online Yayınlanma: 31.12.2021)

\begin{abstract}
Anahtar
Kelimeler

Sismik

yalitım,

Zaman tanım

alanında

analiz,

Artımsal tek

modlu itme

analizi

Öz: Sismik taban yalıtımı günümüzde sismik yüklerin sönümlenmesinde göreli kat ötelemelerini azaltarak yapıların daha az hasarla deprem etkilerinden korunmasını sağlayan özel sistemlerdir. Taban yalıtımlı sistemlerde yapıların dinamik davranışında; kat yükseklikleri, sönümleyici özellikleri ve kullanış biçimleri önem arz etmektedir. Taban yalıtımlı yapıların tasarımına ilişkin en kapsamlı analiz yöntemi gerçek deprem kayıtlarının kullanıldığı zaman tanım alanında analiz yöntemleridir. Artımsal tek modlu itme analizi metodu yapıların mevcut kapasitelerinin belirlenmesinde kullanılan, yapının doğrusal olmayan davranışını ve göçme mekanizmalarının belirlenmesinde kullanılan analiz yöntemlerindendir. Taban yalıtımlı yapılarda ise bu metodun kullanımına literatürde çok az kaynakta rastlanılmıştır. Bu çalışmada da taban yalıtımlı yapı türleri arasında farklı analiz yöntemleri kullanılarak karşılaştırmalı bir değerlendirme yapılması amaçlanmaktadır. Bu kapsamında üç farklı sismik taban yalıtımlı yapı modeli tasarlanmıştır. Taban yalıtımında kurşun çekirdekli kauçuk izolatörler kullanılmıştır. Sismik yalıtımlı yapılarda kat yüksekliklerinin ve katlar arasına yerleştirilen sönümleyicilerin etkileri incelenmiştir. Çalışma sonucunda zaman tanım alanında analiz yöntemi ile sönümleyicilerin doğrusal olmayan davranışlarına ait elde edilen verilerin itme analizlerinden elde edilen veriler ile örtüştügü görülmüş olup, itme analizi yönteminin de sismik yalıtımlı yapı tasarımında etkili bir şekilde kullanılabileceği değerlendirilmektedir.
\end{abstract}

\section{Comparison of Time History and Pushover Methods in Seismic Base Isolated Structures}

Keywords
Seismic
isolation,
Time history
analysis,
Pushover
analysis

Keywords Seismic Time histor analysis

\begin{abstract}
Seismic base isolation is a special system that provides protection of buildings from earthquake effects with less damage by reducing the relative storey drifts in the structures in order to absorb seismic loads. Storey heights, damping properties and usage patterns are important in the dynamic behavior of the structures in base isolated structures. The most comprehensive analysis method for the design of basement isolated structures is the analysis methods in the time domain using real earthquake records. Pushover analysis method is one of the analysis methods used to determine the nonlinear behavior of the structure and the failure mechanisms used to determine the current capacities of the structures. The use of this method in floor isolated structures has been encountered in very few sources in the literature. In this study, it is aimed to make a comparative evaluation among the base isolated building types. Within the scope of this study, 3 different seismic base isolated building models were designed. Lead-rubber bearings are used in the base isolation. The effects of floor heights and isolators placed between floors in seismic isolated buildings were investigated. As a result of the study, it was seen that the data of the nonlinear behavior of the isolators with the analysis in the time history coincided with the data obtained from the thrust analysis, and it is evaluated that the thrust analysis method can be used effectively in seismic isolated building design.
\end{abstract}




\section{GİRIS}

Deprem etkilerinin sönümlenmesinde kullanılan yöntemler bakımından sismik taban izolatörleri yapının zeminle olan bağlantısını keserek yatayda hareketi sağlamaktadır. Örneğin kurşun çekirdekli kauçuk izolatörler, deprem esnasında kauçuk malzeme düşeyde rijitliği yatayda ise esnekliği sağlayarak göreli kat ötelemelerinin azaltılmasını sağlamaktadır. Kurşun malzeme ise sahip olduğu plastisite özelliği nedeniyle yüksek sönümü sağlamaktadır. Bu sayede kauçuk ve kurşun birlikte çalışarak deprem etkilerinin azaltılmasına yardımcı olmaktadır. Taban izolatörleri kullanılarak, herhangi bir deprem sonucu meydana gelen kuvvetli yer hareketlerinin oluşturduğu titreşim etkileri öncelikle karşılanmakta ve üst yapıya gelebilecek deprem kuvvetleri azaltılmaktadır. Ayrıca üst yapı sisteminde oluşacak göreli kat ötelemeleri de azaltılarak taşıyıcı elemanların hasar alması da engellenmektedir. Bunlara ilave olarak taşıyıcı olmayan elemanların hasar alması engellenerek, eşya, makine teçhizat vb. unsurların hareket etmesi, hasar alması ve devrilmesi de önlenerek kullanılabilirlik ve iş sürekliliği açısından devamlılık sağlanabilmektedir (Şekil 1).
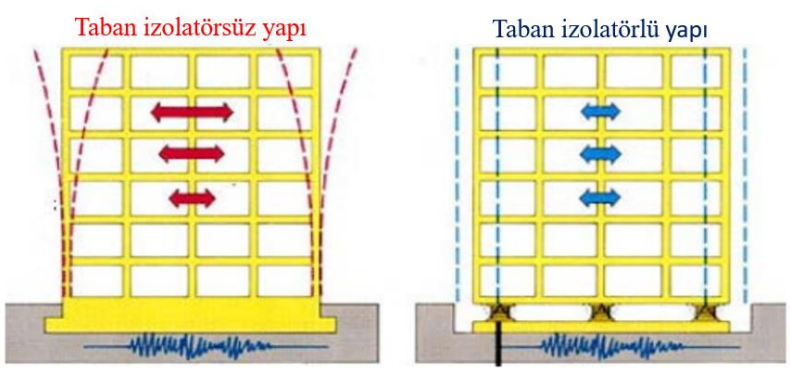

Şekil 1. Sismik yalıtımlı yapıların davranışı [1]

Yalıtım birimlerinin yerleşimi yapı temelinde ya da katlar arasında gerçekleştirilebilmektedir. Yalıtım birimlerinin sonradan yerleştirilmesi işlemi, alt yapı kolonlarının yalıtım birimi boyutlarında kesilmesi ve hidrolik krikolar yardımı ile üst yapının kaldırılarak ara bölgeye yalıtım birimlerinin yerleștirilmesi şeklindedir (Şekil 2).
Literatürdeki kaynaklar incelendiğinde taban izolatörlerinin kullanımı çok eskiye dayanmaktadır. Yaklaşık 1400 yıl önce uzak doğu ülkelerinde inşa edilen ve Pangoda adı ile bilinen kutsal tapınaklar işlev bakımindan pasif kontrol sistemlerinin temelini oluşturmaktadır. Çoğunlukla ahşap türde inşa edilen bu yapıların temel inşaatında silindir ağaç gövdesi parçaları kullanılmaktadır. Ahşaplar, oyulmuş daha ince ve daha dar yuvalara yerleștirilerek neredeyse hiç çivi olmadan birbirine tutturulmaktadır. Olası bir yer hareketi sonucunda bu derzlerdeki ahşap yüzeyler bükülüp birbirine sürtünmektedir. Bu sayede sismik enerjinin üst katlara iletilmesi önlenmektedir (Şekil 3) [2].

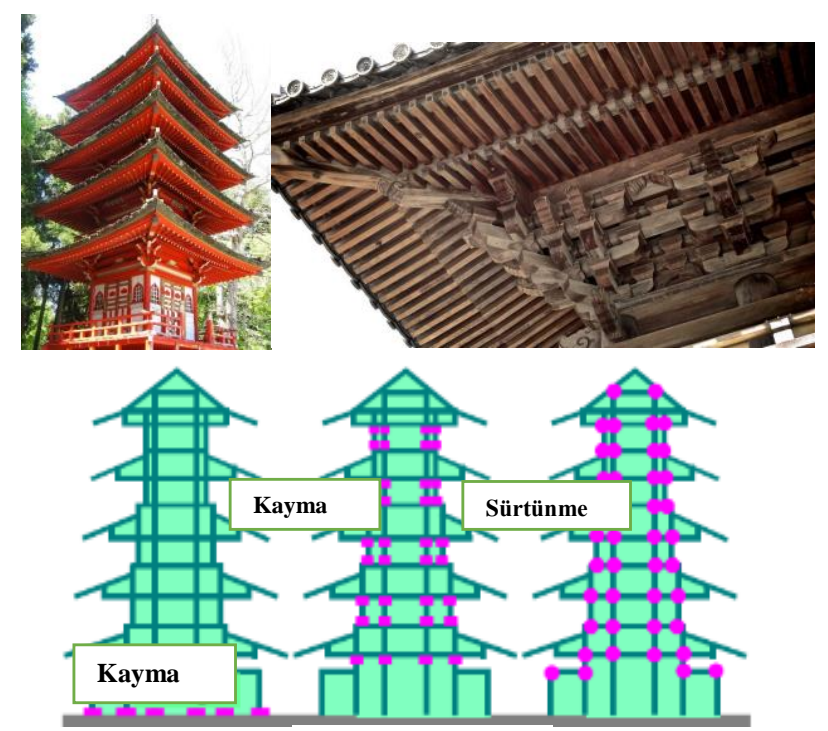

Şekil 3. Pangoda örneği [3].

1870 yılında Jules Touaillon'ın önerdiği taban yalıtımı sistemi de benzer işleve sahiptir (Şekil 4). Yapı temelinde kullanılacak silindir ağaç gövdeleri sürtünme kuvveti etkisiyle sönümü sağlamaktadır.
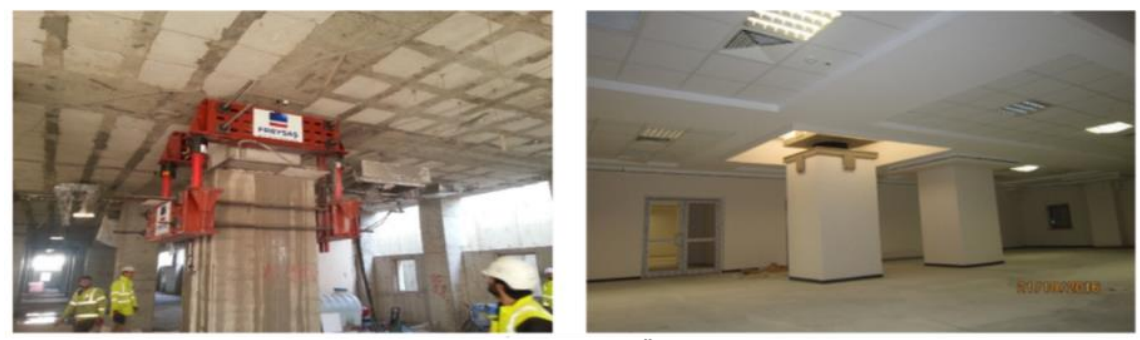

a) Kat askıya alma yöntemi örneği: Marmara Üniversitesi Bașıbüyük EAH
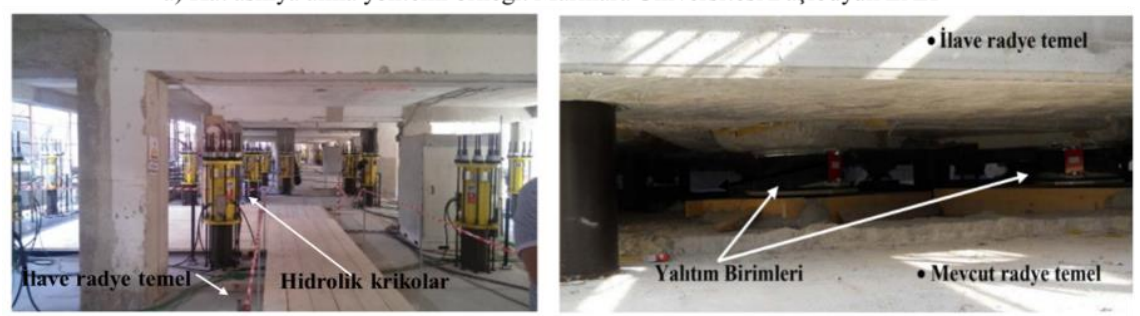

b) Taban izolasyonu yöntemi örneği: L'Aquila 2009 depreminde hasar görmüș betonarme konut binas

Şekil 2. İzolatör uygulamalarına örnekler [1] 


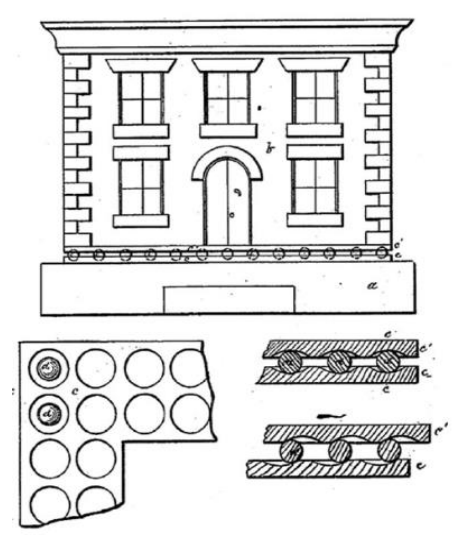

Şekil 4. Jules Touaillon yalıtım sistemi [4]

Geçmişten günümüze depremde hasar alan yapılar incelendiğinde yumuşak zemin ortamlarında aynı bölgede bir yapı devrilirken bir diğer yapı ayakta kalabilmektedir. $\mathrm{Bu}$ durum ana kaya ile yapı temeli arasındaki alüvyon çamur tabakanın gelen sismik dalgaları değiştirmesi ve yapının titreşim davranışını farklılaştırması ile ifade edilebilmektedir. 1906 y1lında İngiliz fizikçi Johannes Avetican Calantarients [5], yapının temeli ile zemin arasına toz ve micir tanelerinden oluşan bir ara tabaka oluşturularak deprem esnasında yatayda hareketin sağlanması ve göreli kat ötelemelerin azaltılması konusunu incelemiş ve bu doğrultuda çalışmalar yapmıştır. Frank Lloyd Wright [6], Tokyo' da 1921-1923 y1llarında Imperial Oteli'ni tasarlamıştır. Otelin temel inşaatında sağlam bir zemin ile alüvyon bir çamur tabakasından oluşan bir zemin ortamında, yapıyı sağlam zemine kazıklarla birleştirerek alüvyon zemin üzerinde gemi gibi yüzen bir yapı planmış ve bu yaklaşım taban izolasyonu fikrinin gelişmesinde önemli bir araç olmuştur. Yapı 1923 yılında Tokyo depremini de hasarsız olarak atlatabilmiştir.

Kauçuk malzeme yatayda düşük düşeyde yüksek rijitliğe sahip esnek bir malzemedir. Eugene Freyssinet [7], kauçuğun mekanik özelliklerini keşfetmiştir. Kauçuğun sahip olduğu mekanik özellikler keşfedildikten sonra 1969 y1lında Yugoslavya'da "Pestolozzi" isimli bir okul binasında ilk kez Kauçuk esaslı izolatörler kullanılmıştır [8]. 1970'lerin ortalarında yüksek sönüme sahip kurşun malzeme ile yüksek esnekliğe sahip kauçuk malzeme tek bir izolatörde toplanarak kurşun çekirdekli kauçuk izolatörler (LRBr) üretilmiştir [9].

Taban izolatörleri ile ilgili sayısal çalışmalar incelendiğinde Providakis C.D. [10], taban yalıtımlı kompozit yapıların itme analizini gerçekleştirmiştir. Sonlu elemanlar yöntemine dayalı analiz yapan ETABS yazılımını kullanarak kompozit bir yapının itme analizi sonucunda tabanında meydana gelen kesme kuvvetlerinin ve dönme oranlarını karşılaştırmıştır. İzolatör kaynağına yakın konumda bulunan yapı elemanlarının izolatörler için kritik olduğunu belirtmiştir.

Gökhan E.[11], taban izolatörlerinin betonarme yapılarda taşıyıcı sistem davranışı üzerinde etkilerini araştırmıştır. Çalışmasında deprem güvenliğinin artırılmasında tercih edilen perde ile güçlendirme ve taban izolatörleri kullanılarak deprem güvenliğinin artırılması yöntemlerini karşılaştırmıştır. Çalışma sonucunda, yap1 tasarımında olası yüksek kat ötelemelerinin önlenmesi ve yatayda rijitliği arttırmak amaciyla kullanılan perde sistemlerinin, yapı periyodunu azaltarak kat ivmelerinin artmasına neden olduğunu belirmiştir. Taban izolatörlerinin kullanıldığı durumda ise göreli kat ötelemelerinin azaldığ olarak kat ivmelerinin azaldığı görülmüş ayrıca yapıya etki eden deprem yüklerinin de küçüleceği belirtmiştir. Deprem sırasında izolatör katında meydana gelebilecek yer değiştirmeleri engelleyecek mimari tasarım detaylarından kaçınılması gerektiğini vurgulamıştır.

Toker M. [12], "Elastomer Esasl1 Deprem İzolatörlerinin" kuvvet ve gerilme analizlerini yapmıştır. Performansı yükseltilmiş yeni nesil elastomer çekirdekli deprem izolatörü tasarlamayı hedeflemiştir. Taban yalıtımlı yapılarda karşılaşılan en büyük problem büyük yer değiştirmelerden kaynaklı stabilite problemidir. İzolatör sistemlerinin kapasitesinin aşılması durumunda tekrardan yenilenmesi zahmetli ve maliyetli olmaktadır. Taban yalıtımı sistemleri yüksek binalarda yap1 periyodunda çok büyük artışa neden olabileceğinden uygulanamamaktadır. Mirkelam ZA. ve Derdiman MK. [13], taban yalıtımının yüksek binalarda da uygulanabilmesi için klasik taban yalıtımı sistemi yerine, yapı katları arasına yerleştirilecek izolatörlerin temel izolasyonu ile birlikte binanın depremsel yalıtım performansını nasıl etkilediğini araştırmıştır. Çalışmasında farklı yükseklikteki düzenli ve düzensiz betonarme bina modellerinin her biri için üç farklı taban yalıtımlı, dokuz değişik ilave yalıtımlı model üzerinde çalışmıştır. Yalıtım parametreleri seçilirken, tabandaki yalıtım rijitliğinin katlar arasındaki rijitlik değerlerine göre düşük tutularak orta katlarda oluşabilecek yüksek yer değiştirme problemlerine çözüm üretilebileceği sonucuna varmışlardır. Deprem kuvvetlerinin üst yap1 katları arasına dağıtılması hem tepe noktası toplam yer değiştirmesinin hem de kat ivmelerinin azaltılmasını sağlayacaktır.

Doudoumis N. ve ark. [14], taban yalıtımlı yapılarda statik itme analizi ve zaman tanım alanında analiz yöntemlerini karşılaştırmıştırlar. Dört katlı betonarme bir yapı için her iki yöntem ile yapılan analiz sonuçlarının örtüştüğünü belirtmişlerdir.

Severcan MH. ve ark. [15], farklı yüksekliklerdeki yapılar için taban yalıtımının yapıların dinamik davranışına etkilerini araştırmış ve maliyet analizi yapmışlardır. Sürtünmeli sarkaç izolatörlerin düşük ve orta katlı yapıların deprem etkilerine karşı davranışını olumlu etkilediği görülmüştür. Yüksek yapılarda ise maliyet ve performans bakımından kullanımı uygun görülmemiştir.

$\mathrm{Bu}$ çalışmada sismik yalıtımlı üç farklı yapı modelinin deprem etkileri altında davranışı incelenmiştir. Taban yalıtımlı 4 ve 8 katlı tipik özelliklere sahip iki bina ve 8 katlı yapının dördüncü kat kolonlarının alt uçlarına yerleştirilmiş sismik izolatörlerin etkisi araştırılmıştır. 
Hem farklı kat adedine sahip yapılar için hem de katlar arası izolatör kullanıldığında tek modlu artımsal itme analizi ve zaman tanım alanında analiz sonuçlarının karşılaştırılması yapılmıştır. Burada hem farklı bina yüksekliklerine sahip yapılar üzerinden hem de ara katlarda da sismik yalıtım aracı olması durumları için iki farklı analiz yöntemi kullanılarak yapılan analiz sonuçlarına göre değerlendirme yapılması çalışmanın özgünlüğünün önemli bir göstergesidir.

\section{MATERYAL VE METOT}

Taban yalıtımlı yap1 tasarımında Türkiye Deprem Yönetmeliği, 2018'de etkin deprem yükü yöntemi, mod birleştirme yöntemi ve zaman tanım alanında doğrusal olmayan hesap yöntemleri kullanılmaktadır. Taban yalıtımlı yapı tasarımında taban yalıtımsız yapıların tasarım esaslarından farklı olarak yapının bulunduğu zemin türü, yapı sisteminin periyodu, kat adedi, burulma kontrolleri, sönüm oranları farklılık göstermektedir [16]. Mod birleştirme yöntemi ve zaman tanım alanında hesap edilen yalıtım birimi yer değiştirmelerinin etkin deprem yükü yöntemine göre hesap edilen yer değiştirme değerlerinin \% 80'inden az olmaması gerekmektedir. Bu nedenle bu çalışmada etkin deprem yöntemine göre yalıtım sistemi tasarlanmış ve zaman tanım alanında ve mod birleştirme yöntemlerine göre analizler gerçekleştirilmiştir. Zaman tanım alanında analizde, ölçeklenmiş deprem ivme kayıtları yapıya doğrudan etki ettirilirken artımsal tek modlu itme (pushover) analizinde yatay yükler, taşıyıcı sistem belirli bir limit yer değiştirme değerine ulaşana kadar adım adım arttırılarak etki ettirilmektedir (Şekil 5).

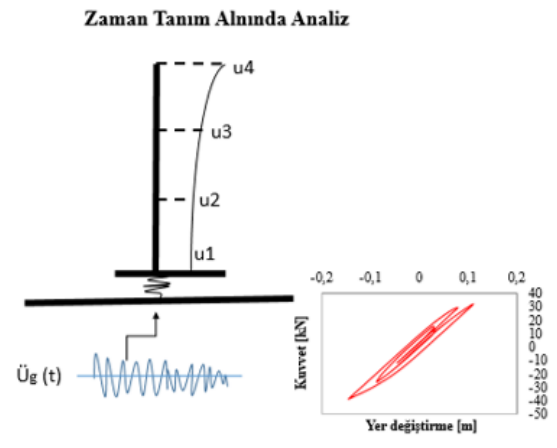

a)

Zaman tanım alanında analiz

Statik İtme Analizi

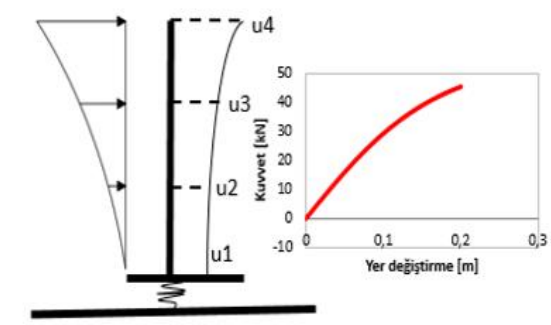

b) Statik itme analizi

Şekil 5. Zaman tanım alanında analiz (a) ve statik itme analizi (b)

Taban yalıtımlı yapıların hesabında sistem, alt yapı ve üst yapı olarak iki farklı kısımda değerlendirilerek ele alınmaktadır. TBDY 2018' de üst yapı sistemi, 50 yılda aşılma olasılığı \%10 olan (DD-2 ) tasarım deprem yer hareketi etkisinin üst sınırı için dayanıma göre tasarım yöntemine göre hesap edilerek sınırlı hasar performans düzeyini karşılamalıdır. Alt yapı sistemi ise 50 yılda aşılma olasılığ1 \%2 (DD-1) olan en büyük deprem yer hareketi düzeyinin (DD-1) alt sınır değerleri için şekil değiştirmeye göre tasarım hesap yöntemlerine göre kesintisiz kullanım performans seviyesini karşılamalıdır. Etkin deprem yükü yöntemine göre kurşun çekirdekli kauçuk izolatörlerin hesabına ilişkin tasarım şeması Şekil 6'da sunulmuştur.

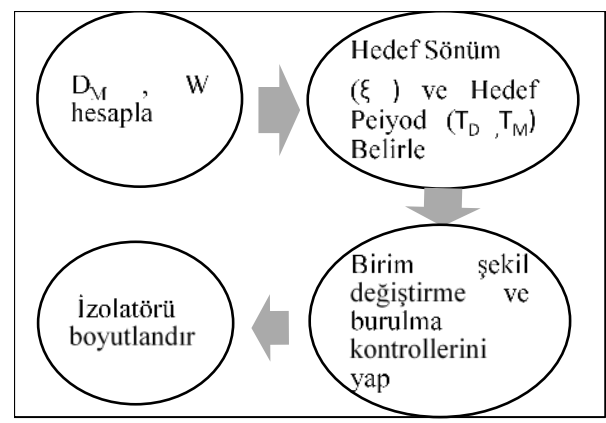

Şekil 6. Etkin deprem yükü yöntemine göre izolatör tasarım şemas [16].

$\mathrm{D}_{\mathrm{M}} \quad$ : DD-1 için yalıtım sistemi etkin rijitlik merkezinde oluşacak yer değiştirme

DD-1 : 50 yılda aşılma olasılığ $\% 2$ olan deprem yer hareketi düzeyi

W : Yapı ağırlığı

$\mathrm{T}_{\mathrm{M}} \quad$ : DD-1'e göre hesaplanan yapı periyodu

$\mathrm{T}_{\mathrm{D}} \quad$ : DD-2'ye göre hesaplanan yapı periyodu

$\xi \quad:$ Yalıtım birimi yer değiştirmelerinde hesaplanan etkin sönüm yüzdesi

DD-2 : 50 yılda aşılma olasılığı \%10 olan deprem yer hareketi düzeyi

\section{SAYISAL ÇALIŞMA}

$\mathrm{Bu}$ çalışma kapsamında malzeme ve kesit özellikleri aynı olan ancak farklı yapı yüksekliklerine sahip ve katlar arası sismik yalıtım araçlarının olduğu üç farklı yap1 modeli incelenmiştir. Birinci model 4 katlı, ikinci model 8 katlı ve üçüncü model ise 8 katlı olup ilave olarak 4. katında kurşun çekirdekli kauçuk sönümleyiciler bulunmaktadır. Yap1 modelleri 50x50 cm boyutlarında betonarme kolonların ve $30 \times 50 \mathrm{~cm}$ boyutlarında betonarme kirişlerin oluşturduğu betonarme-çerçeveli sistemlerdir (Şekil 7). Analizlerde sonlu elemanlar yöntemine dayalı hesap yapan Sap2000 yazılımı kullanılmıştır. Kurulan sonlu eleman modelinde taşıyıcı sistemi oluşturan kolon ve kirişler düğüm noktalarından altı serbestlik derecesi olan çubuk elemanlar ile modellenmiştir.

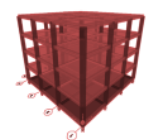

Model 1

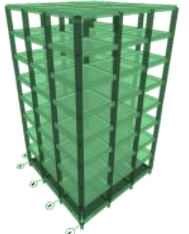

Model 2

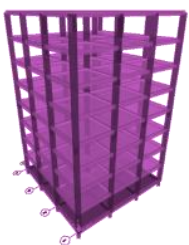

Model 3
Şekil 7. Sismik yalıtımlı yapı modelleri 
Sismik yalıtım hesaplamalarında izolatör tasarımı için hedef bir periyod belirlenmekte ve bu periyod değerlerine göre birtakım varsayımlar sonucu izolatör özellikleri elde edilmektedir. Hedeflenen periyoda uygun tasarım rijitlikleri TBDY 2018'de tanımlanan DD-1 ve DD-2 deprem düzeyleri için güvenlik koşullarını sağladığında tasarım tamamlanmaktadır. Yalıtımda kullanılan sismik sönümleyici özellikleri Tablo 1'de yapı özelikleri ise Tablo 2'de verilmiştir. Yapı özellikleri incelendiğinde standart koşullar göz önünde bulundurulmuş zemin sınıfı için sismik taban yalıtımına uygun olan bir zemin sınıfı tercih edilmiştir.

Tablo 1. İzolatörün mekanik özellikleri

\begin{tabular}{lll}
\hline $\begin{array}{l}\text { Kurşun çekirdekli kauçuk sönümleyici } \\
\text { özellikleri }\end{array}$ & Model 1-3 & Model 2 \\
\hline $\begin{array}{l}\text { Düş̧ey doğrultu için lineer rijitlik }(\mathrm{kN} / \mathrm{m}): \\
\mathrm{k}_{\mathrm{v}}\end{array}$ & 568630,4 & 680300,5 \\
\hline $\begin{array}{l}\text { Yatay doğrultu için nonlineer rijitlik } \\
(\mathrm{kN} / \mathrm{m}): \mathrm{k}_{\mathrm{e}}\end{array}$ & 477 & 400 \\
\hline $\begin{array}{l}\text { Yatay doğrultu için lineer rijitlik }(\mathrm{kN} / \mathrm{m}): \\
\mathrm{k}_{1}\end{array}$ & 3591,826 & 4297,204 \\
\hline $\begin{array}{l}\text { Yatay doğrultu için akma dayanımı }(\mathrm{kN}): \\
\mathrm{F}_{\mathrm{y}}=\mathrm{F}_{\mathrm{Q}}\end{array}$ & 51,38 & 51,38 \\
\hline $\begin{array}{l}\text { Yatay doğrultuda akma sonrası rijitliğin } \\
\text { akma öncesi rijitliğe oranı: } \mathrm{k}_{2} \mathrm{k}_{1}\end{array}$ & 0,1 & 0,1 \\
\hline Tasarım yer değiştirmesi $(\mathrm{mm}): \mathrm{D}$ & 300 & 364 \\
\hline Akma yer değiştirmesi $(\mathrm{mm}): \mathrm{D}_{\mathrm{y}}$ & 0,012 & 0,014 \\
\hline
\end{tabular}

Tablo 1'de verilen 4 katlı Model 1'e ait izolatör özelikleri incelendiğinde yapı ağırlığının daha düşük olması nedeniyle daha düşük bir periyod hedeflenmiştir. 2 numaralı modelde ise Model 1'in iki katı bir yap1 ağırlığı olacağından yapı daha yüksek periyoda sahip olacaktır. Model 3'de ise ara katta izolatör kullanımı göreli kat ötelemelerinin düşürülmesini sağlayacak ve izolatörlere düşen normal kuvvetin azalmasında etkili olacaktır.

Tablo 2. Yapı özellikleri

\begin{tabular}{ll}
\hline Zemin & ZB \\
\hline Beton sınıfi & C 35/40 \\
\hline Celik sınıfi & B420C \\
\hline Kat yüksekliği & $3 \mathrm{~m}$ \\
\hline Kiriş boyutu & $300 \times 500 \mathrm{~mm}$ \\
\hline Kolon boyutu & $500 \times 500 \mathrm{~mm}$ \\
\hline Döşeme kalınlığı & $140 \mathrm{~mm}$ \\
\hline
\end{tabular}

Analizlerde kullanılan deprem kayıtlarının özellikleri Tablo 3'te verilmiştir. Deprem kayıtları seçilirken deprem büyükleri birbirine yakın olan ve tasarım deprem spektrumuna uygun 12 çift deprem yer hareketi kaydı seçilmiştir. Deprem kayıtları Pacific Earthquake Engineering Research Center (PEER) kuvvetli yer hareketi veri tabanından [18] elde edilmiş olup TBDY 2018 koşullarını sağlayacak şekilde seçim yapılmıştır.

Tablo 3. Deprem kayıtlarının özellikleri

\begin{tabular}{|c|c|c|c|c|c|}
\hline Kayıt No & Deprem & Tarih & İstasyon & Kayıt & Büyüklük \\
\hline 158 & Imperial Valley-06 & 1979 & Aeropuerto Mexicali & IMPVALL.H_H-AEP045, AEP315 & 6,53 \\
\hline 159 & Imperial Valley-06 & 1979 & Agrarias & IMPVALL.H_H-AGR003, AGR273 & 6,53 \\
\hline 160 & Imperial Valley-06 & 1979 & Bonds Corner & IMPVALL.H_H-BCR140, H-BCR230 & 6,53 \\
\hline 667 & Whittier Narrows-01 & 1987 & Northridge - 17645 Saticoy St & WHITTIER.A_A-STC090, A-STC180 & 5,99 \\
\hline 801 & Loma Prieta & 1989 & San Jose - Santa Teresa Hills & LOMAP_SJTE225, SJTE315 & 6,93 \\
\hline 821 & Erzican, Turkey & 1992 & Erzincan & ERZINCAN_ERZ-EW, NS & 6,69 \\
\hline 1048 & Northridge-01 & 1994 & Northridge - 17645 Saticoy St & NORTHR_STC090, STC180 & 6,69 \\
\hline 1147 & Northridge-01 & 1994 & Newport Bch - Newp \& Coast & KOCAELI_ATS000, ATS090 & 6,69 \\
\hline 1158 & Kocaeli, Turkey & 1999 & Duzce & KOCAELI_DZC180, DZC270 & 7,51 \\
\hline 1165 & Kocaeli, Turkey & 1999 & Izmit & KOCAELI_ZZT090, IZT180 & 7,51 \\
\hline 1722 & Northridge-06 & 1994 & Northridge - 17645 Saticoy St & NORTH392_STC090, STC180 & 5,28 \\
\hline 4451 & Montenegro, Yugoslavia & 1979 & Bar-Skupstina Opstine & MONTENE.GRO_BSO000, BSO090 & 7,1 \\
\hline
\end{tabular}

\subsection{Bulgular}

Deprem verileri TBDY 2018 de tanımlamam “deprem kayıtlarının basit ölçekleme yöntemi ile ölçeklenmesi" yöntemine göre tasarım spektrum eğrisi dikkate alınarak ölçeklendirilmiş ve sonuçlar Şekil 8'de karşılaştırmalı olarak verilmiştir. Sismik yalıtımlı yapılarda zaman tanım alanında analiz yapılırken normal yapılardan farklı olarak ölçeklendirme esaslarında kullanılan periyod aralığında farklılıklar görülmektedir. Normal yapılarda yap1 hâkim periyodunun 0,2 katı ile 1,5 katı arasında deprem kayıtlarının ortalama spektrumlarının tasarım spektrumunun altında olmaması gerekmektedir. Taban izolatörlü yapılarda ise en büyük yer değiştirme altında deprem yalıtımlı binanın üst sınır değerleri ile hesaplanmıș etkin titreșim periyodunun 0,5 katı ile 1,25 katı arasında deprem kayitlarının ortalama spektrumlarının tasarım spektrumunun 1,3 katının altında olmaması gerekmektedir [16].

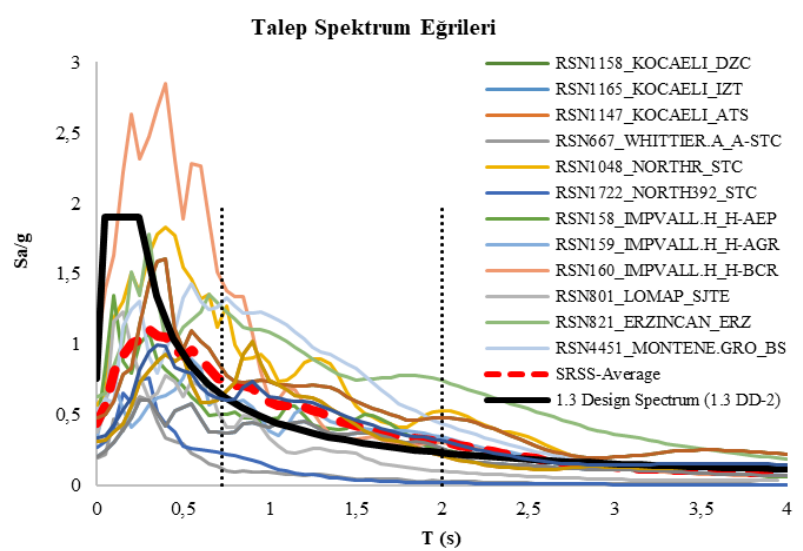

Şekil 8. Ölçeklendirilmiş spektrum eğrileri

Öncelikle yukarıda tanımlanan taban yalıtım özellikleri kullanılarak belirtilen yapı modellerinin modal analizleri yapılmıştır (Şekil 9). Modal analizde öncelikle kurulan modeller, bir özdeğer problemi olarak ele alınmaktadır. Özdeğer probleminde, rijitlik ve kütle matrislerine bağlı 
olarak yazılan frekans denklemi üzerinden öncelikle özdeğerler yani serbest titreşim frekans ve periyodları ve bunlara bağlı olarak da öz vektörler yani titreşim şekilleri (mod şekilleri) elde edilmektedir. Kırmızı renkli yap1 Model 1'i yeşil renkli yapı Model 2'yi ve pembe renkli yapı ise Model 3'ü temsil etmektedir. Yapıların hâkim modlarının hedeflenen periyoda yakın serbest titreşime sahip olduğu görülmüştür.
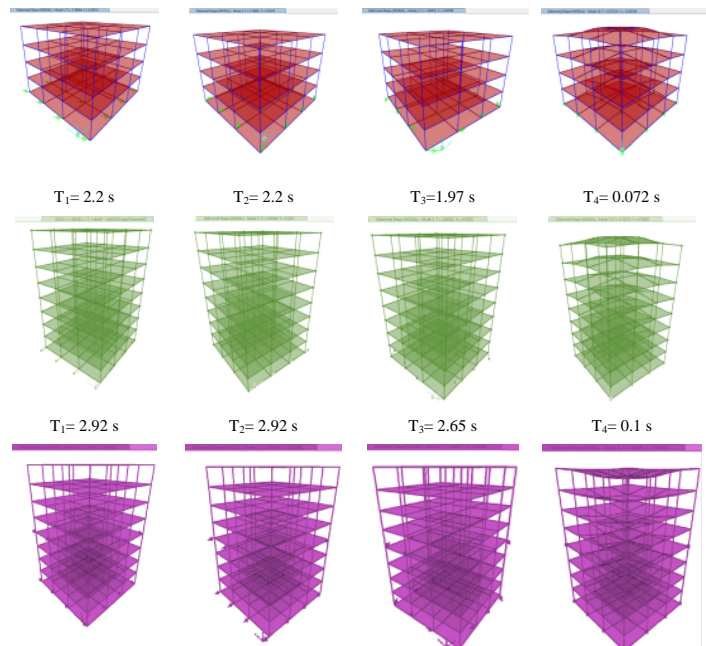

$T_{1}=1.86 \mathrm{~s}$

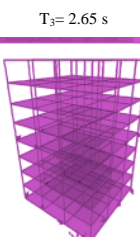

$\mathrm{T}_{3}=1.70 \mathrm{~s}$

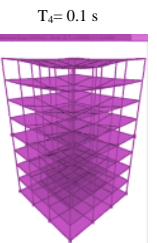

$\mathrm{T}_{4}=0.065 \mathrm{~s}$

Şekil 9. Sismik yalıtımlı yapı modelleri için serbest titreşim şekilleri

Sismik yalıtımlı yapı modellerinin deprem etkileri altındaki davranışı göstermek adına ölçeklenmiş deprem kayıtlarından RSN 158 depremi altında sistemlerin dinamik analizleri yapılmış ve üç modele ait dinamik davranış şekli Şekil 10'da verilmiştir.

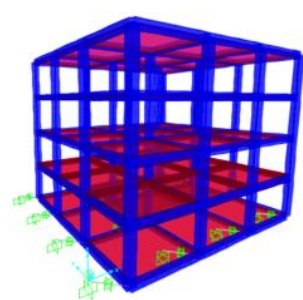

a) Model 1

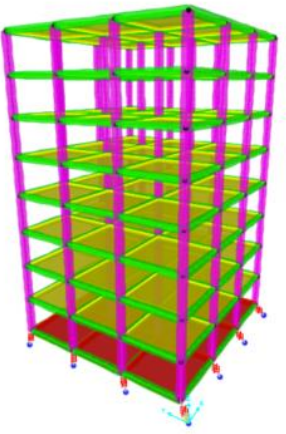

b) Model 2

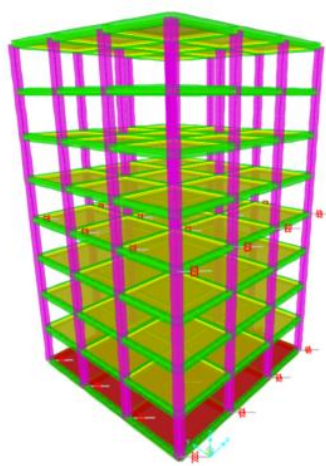

c) Model 3

Şekil 10. Deprem yükleri altında yapıların dinamik davranışı (RSN 158-Maksimum değerleri)

Modal analiz yapıldıktan sonra ölçeklenmiş farklı deprem kayıtları kullanılarak yapılan zaman tanım alanında analiz sonuçlarına göre izolatörlerde meydana gelen histeretik davranışın statik itme eğrileri ile karşılaştırılması yapılmıştır. Zaman tanım alanında analiz sonucunda izolatörlerdeki negatif yönde maksimum yer değiştirme ve dönmeler RSN 1165 'te numaralı deprem kaydı için, pozitif yönde ise maksimum yer değiştirme ve dönmeler RSN 158 numaralı deprem kaydında görülmüştür. $\mathrm{Bu}$ değerlendirmeler doğrultusunda 1 numaralı yap1 modeli için histerezis davranış ve statik artımsal itme analiz sonuçları Şekil 11 'de karşılaştırmalı olarak verilmiştir. Model 1'deki taban izolatöründe; zaman tanım alanında analiz sonucunda elde edilen histerezis davranıș ile statik itme analiz sonucunda elde edilen kuvvet yerdeğiştirme eğrisinin pozitif ve negatif yönde örtüştüğü görülmüştür (Şekil 11). Ayıca mutlak değer olarak her iki ivmezaman kaydı için maksimum değerlerde benzer sonuçlar elde edilmiştir. $\mathrm{Bu}$ da yapılan ölçekleme işleminin gerçekçi olduğu sonucunu ortaya koymaktadır.

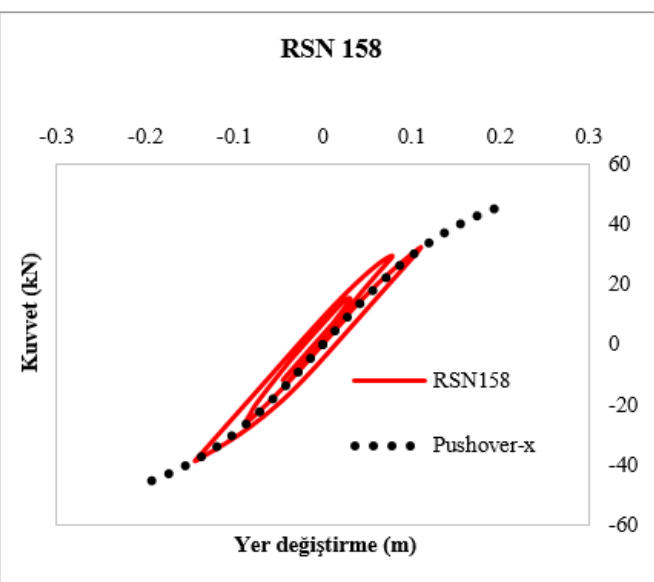

a) RSN 158 depremi histerezis eğrisi ve pushover eğrilerinin karşılaştırılması

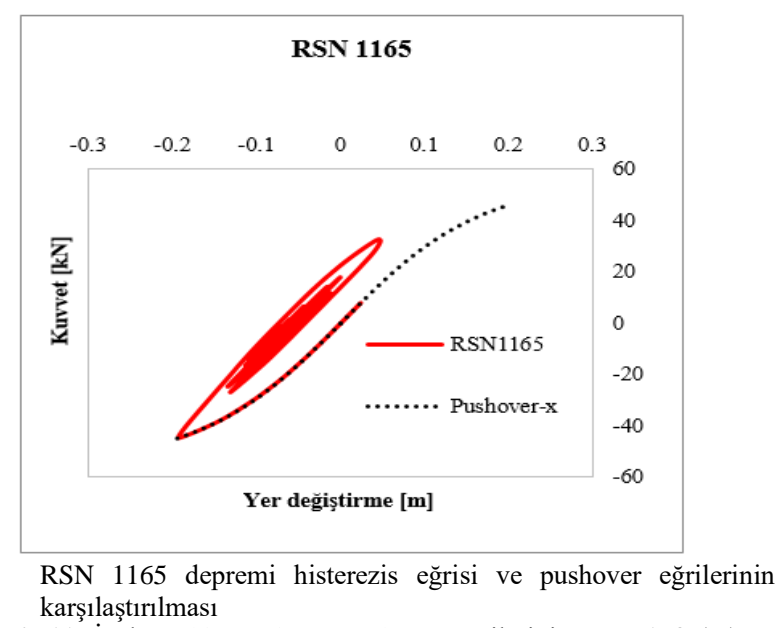

Şekil 11. İzolatör histerezis ve pushover eğrilerinin RSN 158 ( a) ve RSN 1165 (b) için karşılaştırılması

RSN 158 numaralı deprem kaydı kullanılarak yapılan analiz sonuçları ile statik itme analizi sonucunda elde edilen pushover eğrileri 3 farklı model için Şekil 12'de karşılaştırmalı olarak verilmiştir. Öncelikle tüm modellerde kullanılan iki farklı analiz yöntemi için 
izolatörlerin davranışı ve kuvvet-yer değiştirme değerlerinin örtüştüğü görülmüştür. Ayrıca yalıtım birimlerinde meydana gelen yer değiştirme değerlerinin tüm modellerde benzer olduğu gözlemlenmiştir (Şekil 12).

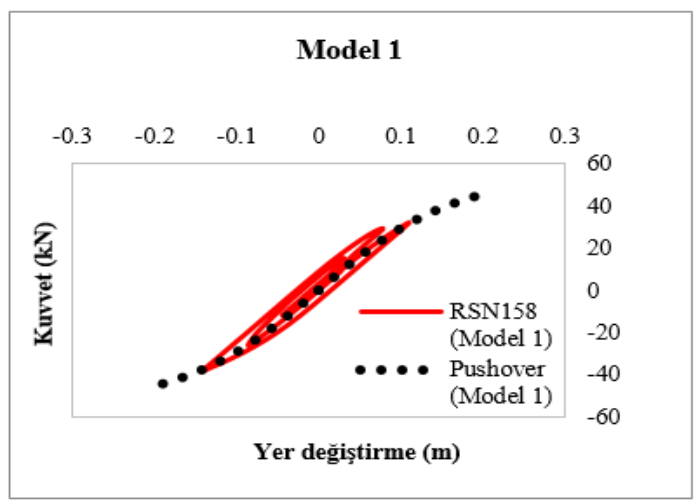

a)

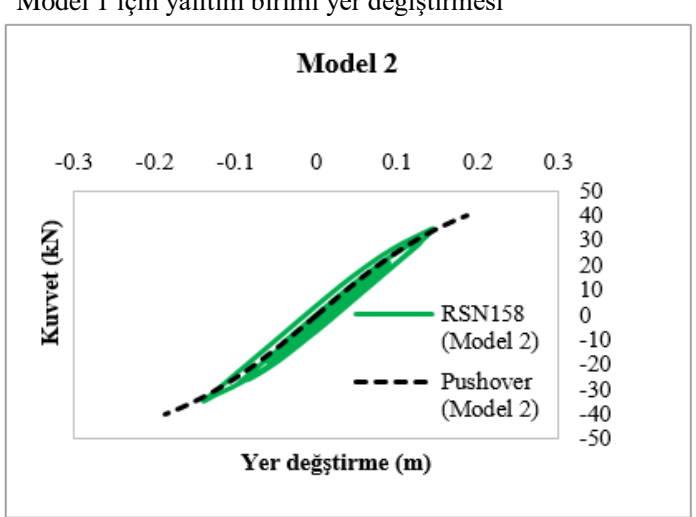

b) Model 2 için yalıtım birimi yer değiştirmesi

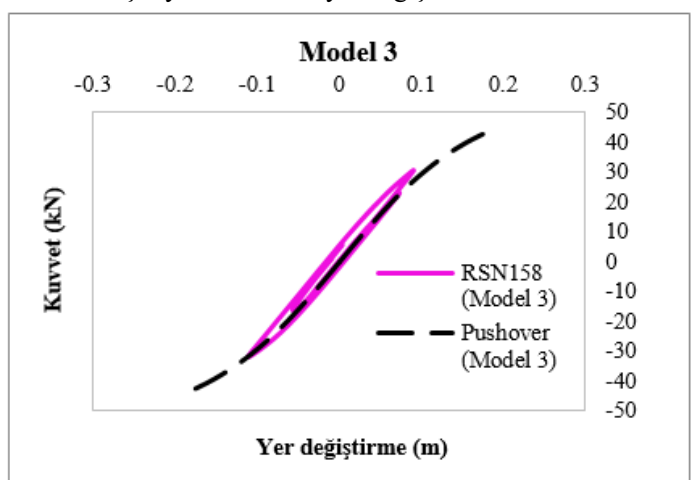

c) Model 3 için yalıtım birimi yer değiştirmesi

Şekil 12. Yalıtım birimi yer değiştirmelerinin model 1 (a), model 2 (b), ve model 3 (c) için karşılaştırılması

RSN 158 deprem kaydı için göreli kat ötelemeleri ve sönümlenen enerji oranları ve düşey yük etkileri altında yalıtım birimindeki yer değiştirmeler 3 farklı model için karşılaştırmalı olarak elde edilmiştir (Şekil 13). Göreli kat ötelemeleri Model 2 ve Model 3'te Model 1'e göre daha düşük çıkmıștır. Bu da, yapı tiplerinin izolatör yerleşimi ve kapasitesinin ayn deprem etkilerinde üst yapı davranışına büyük etki edeceği ve iyi bir tasarımla göreli kat ötelemeleri azaltılarak taşıyıcı sistem elemanlarının hasar almasının kolaylıkla önlenebileceği sonucunu ortaya koymaktadır.

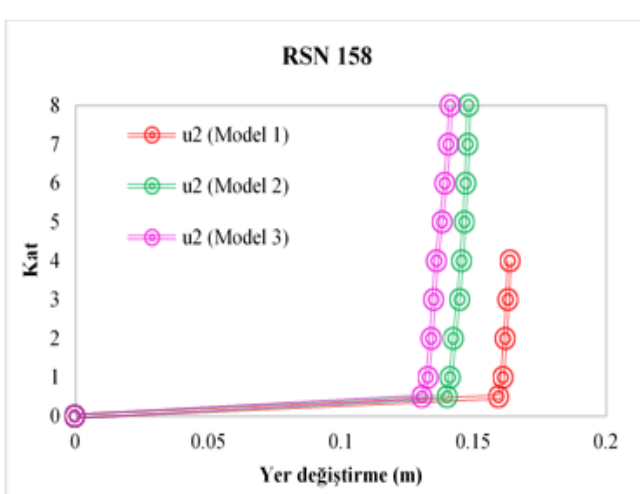

a)

Göreli kat ötelemelerinin karşıllaştırılması

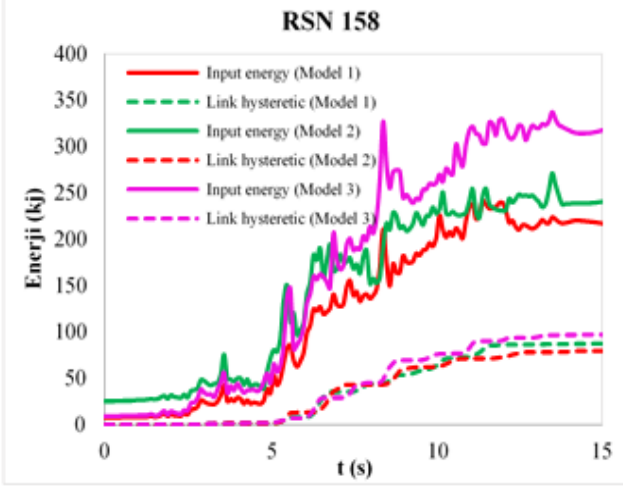

b) Enerji verilerinin karşılaştırılması

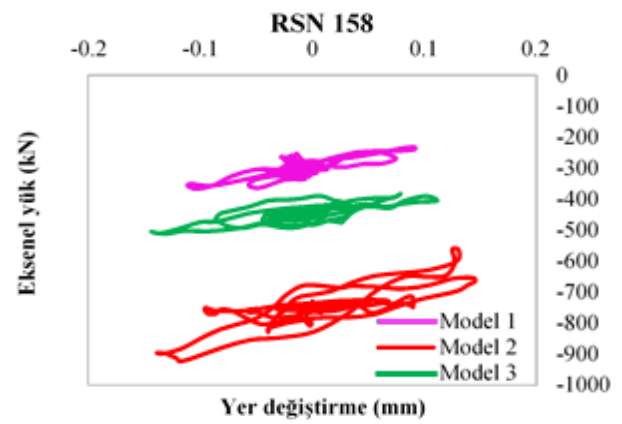

c) Düșey yük etkilerinin izolatörlere etkisi

Şekil 13. RSN 158 depremi için göreli kat ötelemeleri (a) ve sönümlenen enerji oranları (b) ve düşey yük etkilerinin (c) farklı modeller üzerinde karşılaştırmaları

4 katlı taban yalıtımlı yap1 modeli (Model 1), 8 katlı taban yalıtımlı yapı modeli (Model 2) ve 8 katlı tabanda ve ara katta yalıtım sistemi bulunan yapı modeli (Model 3) için artımsal statik itme analizleri sonucunda kapasite eğrileri elde edilmiş ve zaman tanım alanında analiz (TH) sonuçlarından elde edilen maksimum yer değiștirme ve kuvvet ilişkileri karşılaştırmalı olarak elde edilmiştir (Şekil 14). Her iki yöntemle yapılan analiz sonuçlarında yapı tepe noktası yerdeğiştirme değeriyatay kuvvet ilişkisinin örtüştüğü ve statik itme analizinin de zaman tanım alanında analiz kadar etkili sonuç verdiği gözlemlenmiștir. 


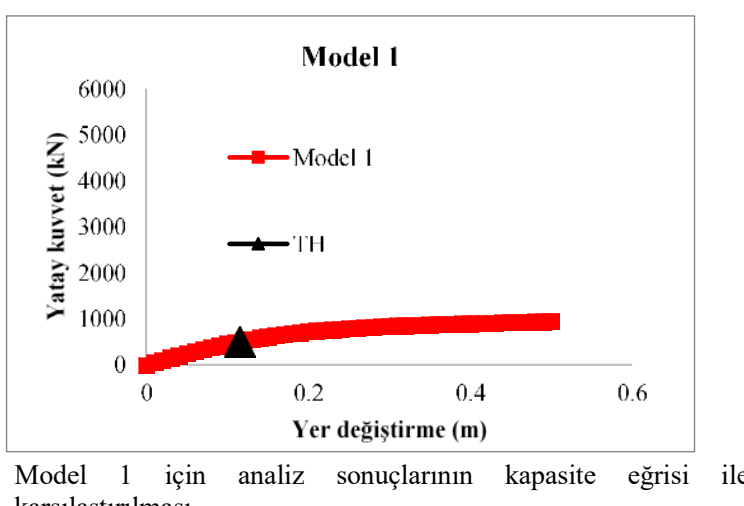
karşılaştırılması

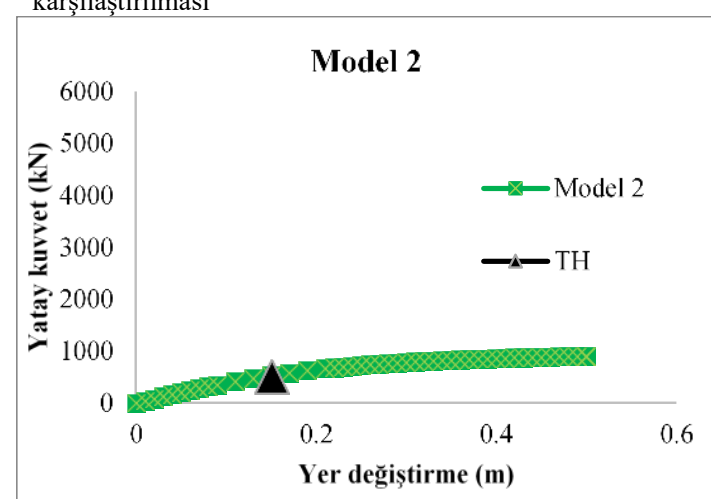

b) Model 2 için analiz sonuçlarının kapasite eğrisi ile karşılaştılması

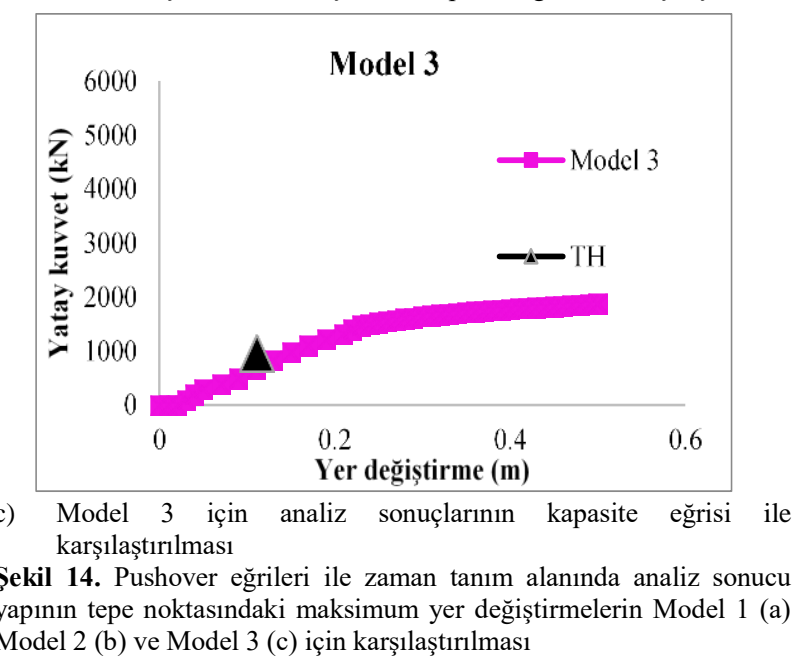

\section{DEĞERLENDİRME VE SONUÇ}

Çalışma kapsamında üç farklı türde yapıya sismik taban yalıtımı uygulanmıştır. Sismik yalıtımlı yapılar zaman tanım alanında analiz yöntemine ve statik itme analizi yöntemlerine göre çözümlenmiş ve yalıtım birimi davranışı incelenmiştir. Ayrıca üst yapı için de göreli kat ötelemelerinin değişimi de elde edilmiştir. Elde edilen bu veriler doğrultusunda;

- Tüm yap1 modelleri için statik itme analizi sonucunda elde edilen yalitım birimi yer değiştirmeleri zaman tanım alanında analiz yöntemi ile elde edilen yalıtım birimi yer değiştirme değerleri ile örtüşmektedir (Şekil 12).

- Kat adedi arttırıldığında yapı ağırlığının artması ile birlikte yalıtım sistemi özelliklerinin yapının periyoduna bağlı olarak değişmesi gerekmektedir (Tablo 1). Sadece taban yalıtımı bulunan düşük katlı yapı ile yüksek katlı yapı davranı̧̧ı incelendiğinde farklı izolatör rijitliklerine sahip olmalarına karşın benzer seviyede sönüm değerleri hesaplanmıştır (Şekil 13.b).

- Yüksek katlı olup yapının orta seviyesinde izolatör sistemi bulunan yap1 ile (Model 3) sadece taban yalıtımı bulunan yapı karşılaştıııldığında (Model 2) göreli kat ötelemelerinde büyük bir farkl1lık olmamakla birlikte ara katta yalıtım biriminin olması tüm katlar için göreli kat ötelemelerinde bir azaltma yapmıştır (Şekil 13.a).

- İzolatör tasarım yer değiştirmelerin aşılmamış olması bakımından değerlendirme yapıldığında ara katta izolatör kullanımı gereksiz maliyete neden olabilmektedir. Ancak daha yüksek deprem etkileri altında göreli kat ötelemeleri de artacağından üst katlarda rijitliği azaltılmış izolatör sistemlerinin kullanımının literatürde de belirtildiği üzere [13] faydalı olabileceği sonucuna varılmıştır.

- Üç farklı yapı modeli içinde hem statik itme analiz sonucunda hem de zaman tanım alanında analiz yöntemlerine göre yapı tepe noktalarında meydana gelen maksimum yerdeğiştirme değerlerinde bir sapma gözlenmemiş̧tir (Şekil 14).

- Yalıtım biriminin oluşturacağı sönüm performansı açsından Model 1'de en fazla sönüm değerleri beklenmesine karşın, 3 modelde de sönüm kapasiteleri yaklaşık olarak aynı oranda oluşmuştur (Şekil 13.b).

\section{1. Öneriler}

Gelecek çalışmalarda yalıtım teknikleri değiştirilebilir. Farklı yalıtım araçları için değerlendirmeler yapılabilir. Farklı yapı modelleri ve türleri üzerinde çalışmanın çeşitliliği artırılabilir. Model 3 en iyi performansı göstermiş ancak maliyet yönünden yalıtım için daha ekonomik çözümler geliştirilebilir. Ara kat izolatör modellemelerinde izolatör rijitliklerinde değişikler yapılarak verim ve performans yüzdeleri araştırılabilir.

\section{KAYNAKLAR}

[1] Şadan, B.D, Tüzün, C. Deprem güçlendirmesinde deprem yalıtım sistemlerinin kullanımı. OBS Proje Mühendislik Müşavirlik Ltd. Şti., İstanbul

[2] Yamahata, N, Goto Y, Ando N. A study on the roof curve of japanese pagodas. journal for geometry and graphics, 2008, 12.2: 193-203.

[3] Karlovic A. [Internet] Shinbashira-pagoda's exceptional earthquake resistance; 2017 [cited 2020 Oct 08 ].Available from: https://medium.com/

[4] Makris, N. Seismic isolation: early history. earthquake engineering \& structural dynamics. 2019.

[5] Naeim F, Kelly JM. Design of seismic isolated structures: from theory to practice. John Wiley \& Sons, 1999.

[6] Imperial Hotel (1923-1968). Old Tokyo. [Internet]. 2020. [cited 2020 Oct 08 ]. Available from: http://www.oldtokyo.com/imperial-hotel-wright/ 
[7] Kelly, J. M, Konstantinidis, D. Mechanics of rubber bearings for seismic and vibration isolation. Chichester, UK: Wiley, 2011.

[8] Garevski MA, James MK, Zisi NV. Analysis of 3D vibrations of the base isolated school building "Pestalozzi" by analytical and experimental approach. Proceedings of the 12th WCEE, Auckland, New Zealand. 2000.

[9] Robinson W. Seismic isolation of civil buildings in New Zealand. 2020.

[10] Providakis CP. Pushover analysis of base-isolated steel-concrete composite structures under near-fault excitations. Soil dynamics and earthquake Engineering. 2008; 28.4: 293-304.

[11] Gökhan, E. Betonarme yapılarda izolatör kullanımının taşıyıcı sistem davranışına etkileri. İstanbul: İstanbul Teknik Üniversitesi; 2009.

[12] Toker, M. Kolon altı sismik izolatör kuvvet analizi. İzmir: Dokuz Eylül Üniversitesi; 2015.

[13] Mirkelam ZA, Mehmet KD. Katları arasında izolatör kullanılan betonarme binalarda sismik yalıtım etkinliğinin belirlenmesi. Fırat Üni. Müh. Bilimleri Dergisi 2016; 28.1: 35-49.

[14] Doudoumis NI, Christos K, Ioannis ND. A comparative study on static push-over and timehistory analysis methods in base isolated buildings. 1st ECEES, Geneva, Switzerland, September, paper. 2006. No. 420.

[15] Severcan MH. ve Şen P. sismik izolatörlü binalarda kat adedi etkisi. Niğde Ömer Halisdemir Üni. Müh. Bilimleri Dergisi. 2019; 8.2: 922-935.

[16]AFAD. Türkiye deprem bölgelerinde yapılacak binalar hakkında yönetmelik. Ankara. 2018.

[17] Toplu E. Sismik yalitıml y yapılarda patlama etkilerinin incelenmesi. Sakarya: Sakarya Üni. 2020.

[18] PEER Ground motion database - PEER Center. 2020. [cited 2020 Oct 08 ]. [Internet]. Available from: http://ngawest2.berkeley.edu/. 